\title{
Flammability of Alcohol-Gasoline Blends in Fuel Tanks
}

\author{
R. VAIVADS, M. F. BARDON and V. K. RAO \\ Royal Military College, Kingston, Ontario, Canada \\ V. BATTISTA \\ Transport Canada, Ottawa, Ontario, Canada
}

\begin{abstract}
This paper examines the relative flammability hazard presented by the fuel tank headspace vapours of various alcohol-gasoline blends, including methanol (M100), ethanol (E100), winter gasoline, summer gasoline and winter and summer blends of M85, E85 and E10. Ignition tests were conducted to establish flammability limits for each of the fuels. Measured limits were compared to those predicted by the RMC multicomponent fuel volatility model and conclusions were drawn as to the comparative hazards of the fuels studied. The model was also used to examine the effect of fuel tank fill level on the flammability limits of the respective blends. The results show the tendency of the flammability limits both to broaden and shift to warmer temperatures with decreasing fill level or increasing alcohol content.
\end{abstract}

KEYWORDS: Flammability, alcohol, ethanol, methanol, gasoline, fuel tanks.

\section{INTRODUCTION}

The vapour produced by the evaporation of motor fuels can create flammable conditions in partially filled fuel tanks during refuelling, and when damage or leaks occur in tanks or other fuel system components. Blends of gasoline and alcohol, with or without additional priming agents, can produce flammable mixtures under conditions which would not normally be hazardous with ordinary gasoline alone.

In a closed container such as a fuel tank, the equilibrium fuel vapour concentration is a property of the particular fuel concerned. It depends upon the temperature and, in the case of mixtures like gasoline, on the proportions of liquid and vapour in the tank. As the 
temperature decreases, the vapour-air mixture in the headspace becomes leaner. Likewise the mixture in a nearly empty tank is leaner than when the tank is nearly full.

Prediction of multi-component fuel behaviour is complex, especially for the very nonideal alcohol-hydrocarbon mixtures. However, a technique has recently been developed to model the volatility characteristics of such blends [1-7]. A version of this technique was used in the present study to analyze the explosion hazard in fuel tanks.

The purpose of this study was to examine the fuel tank headspace vapour hazard presented by various alcohol-gasoline fuel blends and to help determine whether these pose a greater hazard in practice than conventional gasoline fuels.

Three types of experimental measurements were performed. The first, a direct flammability test, consisted of attempting to ignite a homogeneous vapour at various temperatures with a gas turbine igniter. This provided a strong ignition source to establish unambiguous flammability rather than ignitability data. The remaining two tests, vapour pressure measurement and gas chromatographic analysis allowed the experimental vapour phase flammability to be determined. In addition to their direct relevance to explosion hazards, the experimental results were also used to validate the predictions of the mathematical model and the model was in turn used to evaluate the hazard for other conditions and fuels.

\section{FUEL BLENDS EXAMINED}

There were ten fuels examined in this test program, methanol (M100), ethanol (E100), winter gasoline, summer gasoline and both winter and summer blends of M85, E85 and E10. These latter fuel designations refer to blends having the specified volume percent alcohol, the remainder being gasoline. The winter gasoline was a regular unleaded commercial fuel having a Reid Vapour Pressure (RVP) [8] of $90.64 \mathrm{kPa}$ and a specific gravity of 0.732 . The summer gasoline was made up by weathering winter gasoline such that its final RVP was $60.75 \mathrm{kPa}$ and its specific gravity was 0.731 . The ASTM distillation [9] data for these two gasolines can be found in Ref. [10]. These fuels were then used to blend the respective winter and summer grades of M85, E85 and E10.

\section{FLAMMABILITY TEST PROCEDURE}

The general experimental arrangement is shown in Figure 1. The main components included: an insulated temperature controlled room $(2.2 \mathrm{~m} \times 1.5 \mathrm{~m} \times 2.4 \mathrm{~m} \mathrm{high})$ in which temperatures from $-30^{\circ} \mathrm{C}$ to $+40^{\circ} \mathrm{C}$ could be maintained within $\pm 1{ }^{\circ} \mathrm{C}$, a shaker rig to reduce the time needed to attain equilibrium, the test bombs, a gas turbine igniter and temperature monitoring instrumentation. 


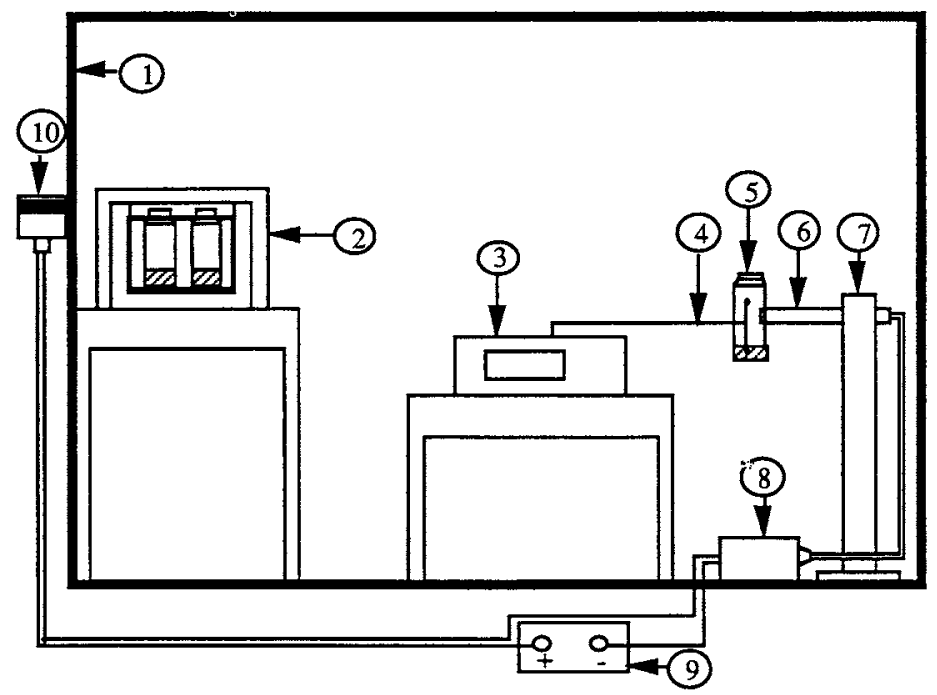

1. Insulated Temperature Controlled Room

2. Shaker Rig

3. Temperature Display

4. Thermocouples

5. Test Bomb

6. Igniter

7. Retort Stand

8. Ignition Exciter

9. 12 Volt Battery

10. Ignition Switch

FIGURE 1: General Arrangement of Apparatus

The test bomb consisted of a $570 \mathrm{~mL}$ translucent high density polyethylene bottle fitted with a screwtop incorporating an aluminum foil rupture disk. The bottle also had two holes drilled in it. The first hole (approximately $3 \mathrm{~mm}$ diameter) served as a feedthrough for the type $\mathrm{K}$ thermocouples used to measure the liquid and vapour temperatures. This hole also allowed the internal pressure to remain at atmospheric pressure independent of the test temperature. The second larger hole (approximately $13 \mathrm{~mm}$ diameter), drilled midway up the side of the bottle, allowed the bottle to be placed over the igniter body for the test. This hole was sealed with an aluminum foil patch taped in place during equilibration. The fuel level was $1 / 30$ full $(19 \mathrm{~mL})$ for all tests. This condition was selected to represent the hazard of a nearly empty fuel tank.

Prior to the flammability tests, the bulk fuel was cooled to $0^{\circ} \mathrm{C}$, then a sample was withdrawn with a syringe and injected into the test bomb. The bomb was then placed in the shaker rig and shaken for not less than 1 hour at the test temperature to ensure that the liquid and vapour attained equilibrium. The bomb was then removed from the rig, placed on the igniter and the switch closed to complete the ignition circuit. The igniter $(0.25 \mathrm{~J})$ was allowed to spark 10 times at a frequency of approximately $2 \mathrm{~Hz}$. All tests were recorded on video tape for later analysis. 
From the modelling point of view, the main task lies in correctly predicting vapour pressure and phase composition. Measurements to validate the models were therefore carried out. The vapour pressure apparatus, shown in Figure 2, consisted of a $0-133 \mathrm{kPa}(0-1000$ torr) capacitance manometer pressure transducer, a vacuum system, a detachable sample vial (A) and interconnecting glassware including a valve to isolate the apparatus from the vacuum system. The total system volume was $22.6 \mathrm{~mL}$.

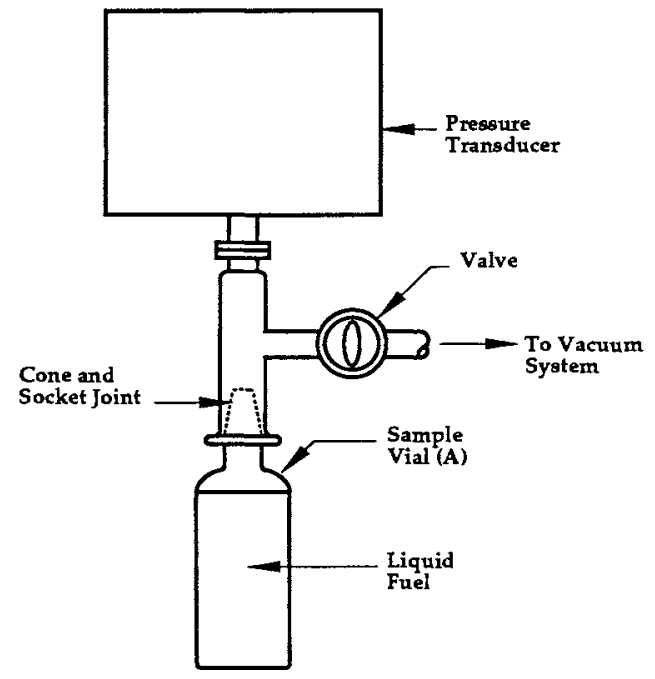

FIGURE 2: Vapour Pressure Measurement Apparatus

Prior to each test, the apparatus was evacuated to remove residual gases and liquids from previous tests. A bulk fuel sample was saturated with air by vigorous agitation and the fuel was cooled to $0^{\circ} \mathrm{C}$. The sample vial was temporarily corked, silicone grease sealant was applied to the periphery of the cone and the vial was immersed in a liquid nitrogen bath. A $0.75 \mathrm{~mL}(1 / 30$ fill level) fuel sample was then removed from the bulk fuel container with a syringe, the cork was removed from the vial and the vial was then charged with fuel, being immediately frozen upon injection. The vial and fuel sample were kept immersed in liquid nitrogen and attached to the main apparatus. The apparatus was then evacuated to a pressure of approximately $1 \mathrm{~Pa}$. When this was completed the apparatus was isolated from the vacuum system by closing the valve. The fuel was then allowed to equilibrate in a temperature controlled bath for at least 1 hour at the test temperature and the transducer reading was noted. Measured pressures were corrected for dissolved air in the fuel sample and residual pressure in the apparatus so as to arrive at a final value of pressure at a given temperature. The procedure used to estimate the magnitude of these corrections is described in Ref. [11]. Only the corrected air free vapour pressure values are reported here. Detailed experimental results can be found in Ref. [10]. 


\section{VAPOUR PHASE COMPOSITION MEASUREMENT PROCEDURE}

The determination of the vapour phase composition was performed at the Fuels and Lubricants Laboratory of the National Research Council of Canada using a Hewlett Packard 5880A Level 4 gas chromatograph equipped with a flame ionization detector. The column used was a $100 \mathrm{~m}$ fused silica capillary column $(0.25 \mathrm{~mm}$ ID) coated with cross-linked methyl silicone $(0.5 \mu \mathrm{m}$ film thickness).

The procedure for this analysis was as follows. A jar of the fuel was refrigerated and allowed to come to equilibrium at $0^{\circ} \mathrm{C}$. A $19 \mathrm{~mL}$ (1/30 fill level) fuel sample was then withdrawn with a syringe and injected into the test bomb. The test bomb was then placed in a constant temperature air bath with the temperature maintained within $\pm-0.1^{\circ} \mathrm{C}$ and allowed to equilibrate for at least one hour at the test temperature during which the sample was periodically shaken. A $0.8 \mathrm{~mL}$ vapour sample was then withdrawn from the bomb using a gas tight syringe and $0.25 \mathrm{~mL}$ of this was injected into the gas chromatograph for analysis. These results were used in conjunction with the vapour pressure measurements to determine the experimental equivalence ratio.

\section{RESULTS AND DISCUSSION}

\section{Flammability Tests}

For the purposes of this study, a successful ignition was defined as a visible flame propagating away from the ignition source on the first spark. The majority of tests were performed to determine the rich limits; however lean limit tests were conducted for E100 and M100 since these fall within the ambient temperature range of interest for automobiles.

The equivalence ratio is defined as the ratio of the actual fuel-oxidant mass ratio (F/O) to the stoichiometric fuel-oxidant mass ratio $(\mathrm{F} / \mathrm{O})_{\mathrm{st}}$, thus:

$$
\phi=\frac{(\mathrm{F} / \mathrm{O})}{(\mathrm{F} / \mathrm{O})_{\mathrm{st}}}
$$

For fuel-lean conditions $0<\phi<1$, for stoichiometric conditions $\phi=1$ and for fuel-rich conditions $1<\phi<\infty$.

Figure 3 shows the results of the ignition test series in comparison with the flammable limit temperatures predicted by the model using lean and rich limit equivalence ratios of $\phi_{L}=0.5$ and $\phi_{R}=2.8$ respectively. These limiting equivalence ratio values are based on the measured flammability data for light hydrocarbon species and alcohols which are given by Zabetakis [12]. The experimental results and predicted limits for 1/30 fill level are shown in Figure 3. In that figure the experimental results show the full range of successful and unsuccessful explosions. 


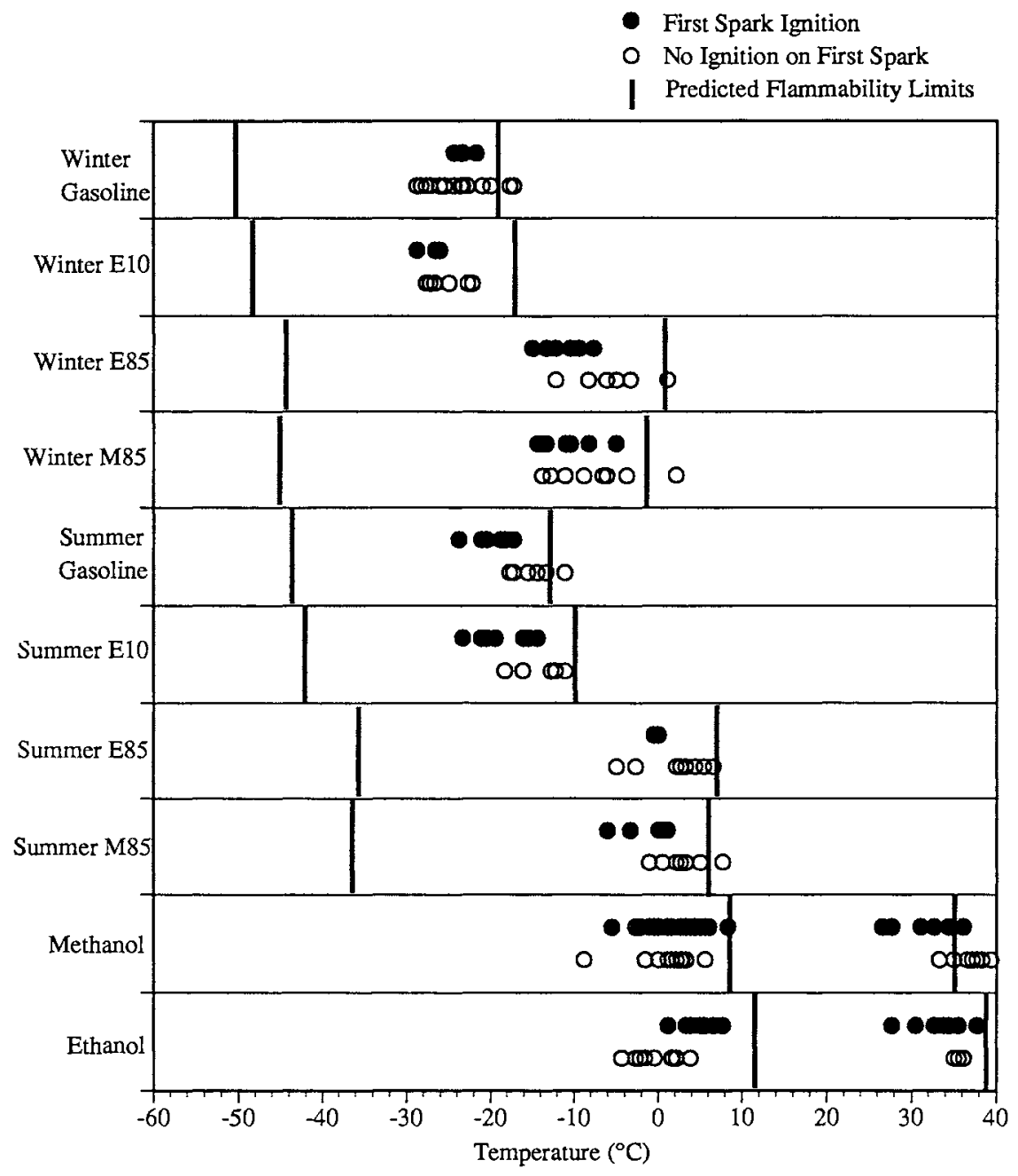

FIGURE 3: Ignition Test Results and Predicted Flammable Ranges for 1/30 Fill Level 
There are no generally applicable standard values for lean and rich temperature limits of fuel blends because of their wide variations in actual composition. However, methanol and ethanol are single component fuels with fixed properties. For example, the usual flammable range cited for methanol is $6-36 \%$ by volume. Since the predicted flammability limits given in this paper are simply the Zabetakis experimental data applied to predicted vapour pressures and phase composition, the "predicted" flammability limits for methanol and ethanol shown in Figure 3 are merely the Zabetakis standard data adjusted for temperature. An interesting feature evident in Figure 3 is that these tests produced explosions outside the accepted lean limit for both alcohols. This is atrributed to the strong ignition source used and shows that, in some cases at least, long established standard data might actually be ignitability limits in the standard flame tube apparatus rather than true flammability limits.

\section{Predicted and Measured Volatility Data}

Validation of the general suitability of the mathematical model was a principal area of this work. Table 1 shows a comparison of measured and predicted vapour pressures and Table 2 shows the measured vapour phase composition for the various blends.

TABLE 1: Summary of Experimental and Predicted Vapour Pressure

\begin{tabular}{|l|c|c|c|}
\cline { 3 - 4 } \multicolumn{2}{c|}{} & \multicolumn{2}{c|}{ Vapour Pressure } \\
\cline { 3 - 4 } & $\begin{array}{c}\text { Temp. } \\
\left({ }^{\circ} \mathrm{C}\right)\end{array}$ & $\begin{array}{c}\text { Experimental } \\
(\mathrm{kPa})\end{array}$ & $\begin{array}{c}\text { Theoretical } \\
(\mathrm{kPa})\end{array}$ \\
\hline Winter & -27 & 7.5 & 4.9 \\
Gasoline & & 7.4 & 4.9 \\
\hline Winter E10 & -27 & 7.3 & 4.5 \\
\hline Winter E85 & -8 & 6.5 & 5.7 \\
& & 7.2 & 5.7 \\
\hline Winter M85 & -6 & 8.1 & 7.8 \\
\hline Summer E85 & 2 & 6.6 & 6.3 \\
\hline Summer M85 & 3 & 9.4 & 9.3 \\
\hline
\end{tabular}

TABLE 2: Results of Gas Chromatographic Analysis

\begin{tabular}{|c|c|c|c|c|c|c|}
\hline & & \multicolumn{5}{|c|}{ Component Mass \% } \\
\hline Fuel & $\begin{array}{c}\text { Temp. } \\
\left({ }^{\circ} \mathrm{C}\right)\end{array}$ & Methanol & Ethanol & Butane & Pentane & Other $\mathrm{HC}$ \\
\hline Winter Gasoline & -27 & 0.00 & 0.00 & 43.18 & 23.49 & 33.33 \\
\hline Winter E10 & .27 & 0.16 & 1.73 & 40.20 & 24.25 & 33.66 \\
\hline Winter E85 & -8 & $\begin{array}{l}0.52 \\
0.45\end{array}$ & $\begin{array}{l}7.18 \\
6.88\end{array}$ & $\begin{array}{l}26.85 \\
32.45\end{array}$ & $\begin{array}{l}29.38 \\
23.61\end{array}$ & $\begin{array}{l}36.07 \\
36.61\end{array}$ \\
\hline Winter M85 & -6 & 16.60 & 0.00 & 25.83 & 27.36 & 30.21 \\
\hline Summer E85 & 2 & $\begin{array}{l}1.05 \\
0.94\end{array}$ & $\begin{array}{l}14.79 \\
13.01\end{array}$ & $\begin{array}{l}12.43 \\
14.13\end{array}$ & $\begin{array}{l}26.44 \\
27.09\end{array}$ & $\begin{array}{l}45.29 \\
44.83\end{array}$ \\
\hline Summer M85 & 3 & $\begin{array}{l}22.99 \\
25.00\end{array}$ & $\begin{array}{l}0.00 \\
0.00\end{array}$ & $\begin{array}{l}13.48 \\
11.11\end{array}$ & $\begin{array}{l}26.07 \\
25.19\end{array}$ & $\begin{array}{l}37.46 \\
38.70\end{array}$ \\
\hline
\end{tabular}


Agreement is generally satisfactory. However, the intended use of the model is to evaluate flammability conditions other than those tested; consequently, the effectiveness in predicting vapour phase equivalence ratio is the issue here, rather than vapour pressure and composition per se. A more relevant comparison can therefore be made by using the experimental vapour pressure and composition data to compute the corresponding vapour phase equivalence ratio. Table 3 shows the results in which "experimental" equivalence ratios are compared to the a priori predictions of the model.

TABLE 3: Summary of Experimental and Predicted Equivalence Ratios

\begin{tabular}{|l|c|c|c|}
\cline { 3 - 4 } \multicolumn{2}{c|}{} & \multicolumn{2}{c|}{ Equivalence Ratio } \\
\hline Fuel & Temp. $\left({ }^{\circ} \mathrm{C}\right)$ & Experimental & Predicted \\
\hline Winter & -27 & 2.60 & 1.92 \\
Gasoline & & 2.56 & 1.92 \\
\hline Winter E10 & -27 & 2.54 & 1.70 \\
\hline Winter E85 & -8 & 2.27 & 2.10 \\
& & 2.47 & 2.10 \\
\hline Winter M85 & -6 & 2.34 & 2.35 \\
\hline Summer E85 & 2 & 2.25 & 2.25 \\
& & 2.28 & 2.25 \\
\hline Summer M85 & 3 & 2.59 & 2.48 \\
& & 2.53 & 2.48 \\
\hline
\end{tabular}

Table 3 shows good agreement between predicted and measured equivalence ratios for the higher alcohol blends but somewhat less satisfactory correlation for Winter gasoline and Winter E10. This is largely attributable to the sensitivity of equivalence ratio to vapour pressure, which the model underpredicts for these two fuels at cold temperatures. The chromatographic analysis shows a relatively high butane content in the vapour phase of both fuels at the test temperature of $-27^{\circ} \mathrm{C}$. Since the model uses a lumped hydrocarbon approach with a mean molecular weight, the results are skewed away from the influence of the more volatile fractions such as butane which tend to dominate at low temperatures. Also the model uses the ASTM distillation curve to predict volatility, thus the predictions at cold temperatures are sensitive to the initial slope of the "volume percent recovered" curve.

Overall, it is concluded that the model gives reasonable flammability predictions over the range of fuels and temperatures studied.

\section{Comparison of Fuel Blend Hazards}

The satisfactory agreement between measured and predicted flammability data provides confidence to use the mathematical model to examine the effect of various parameters such as fill level and fuel blend composition on flammability limits. The model only requires the specific gravity and ASTM distillation curve of the base gasoline, and the alcohol content in the blend. 
Figure 4 shows the variation of predicted equivalence ratio with temperature for the particular fuels studied here at the $1 / 30$ fill level. The differences between winter and summer gasolines and the effect of alcohol addition can be readily discerned from this graph. In particular, it can be seen that both rich and lean flammability limits are similar for blends using either methanol or ethanol combined with the same base gasoline. However, even with a high alcohol content, the characteristics of the vapour are strongly influenced by the volatility of the gasoline fractions. For example, there is a difference of about 8 celsius degrees in the rich limits between winter and summer M85 blends at this fill level.

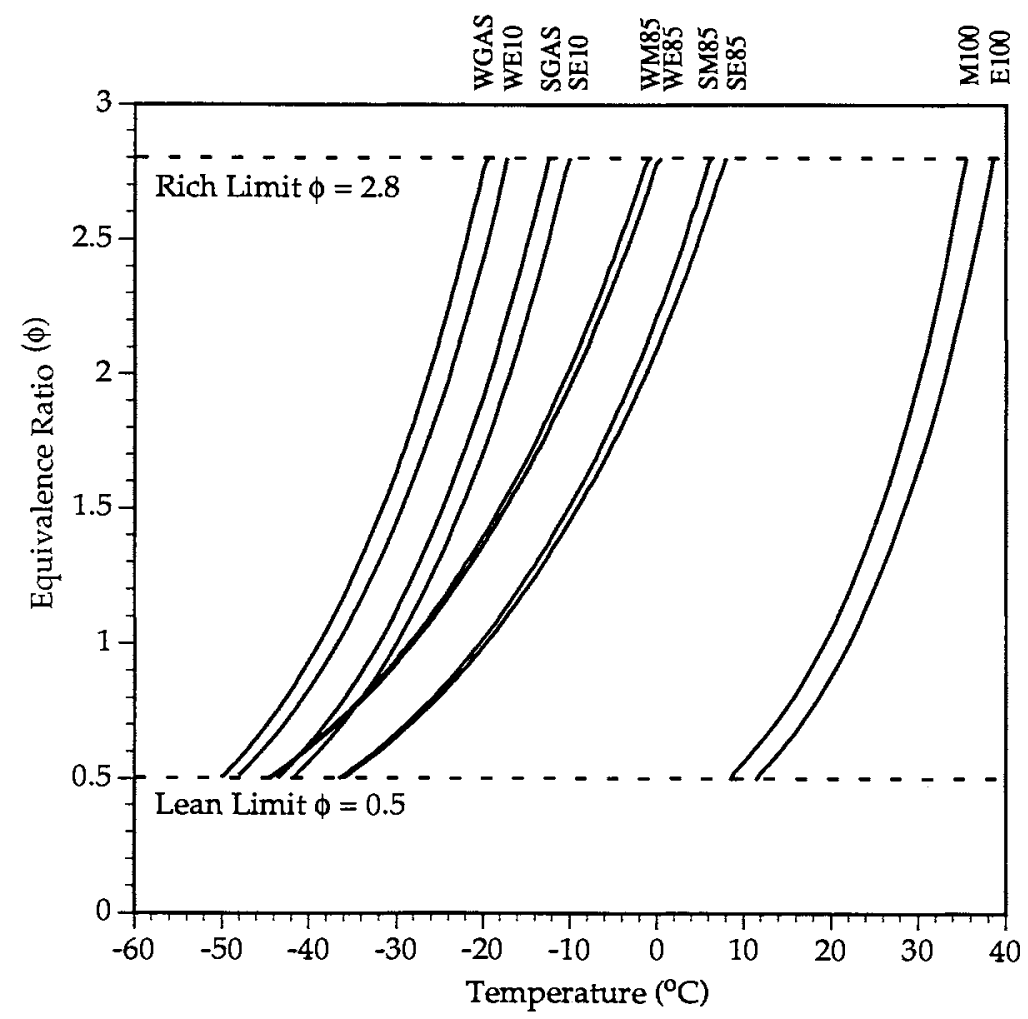

FIGURE 4: Variation of Equivalence Ratio with Temperature for 1/30th Fill Level

Figure 5 shows the calculated flammable range for winter gasoline compared with winter M85 as fuel level in the tank varies. This illustrates the tendency of both rich and lean flammability limits to shift to warmer temperatures as the fill level decreases, especially the M85 rich limit. The increased hazard of M85 is clear, particularly at low fill levels. It is noteworthy, however, that winter gasoline is also hazardous at temperatures common during winter in northern climates. Furthermore, the volatility of current gasoline is decreasing due to evaporative emissions legislation, which increases the risk of tank explosions still further. 


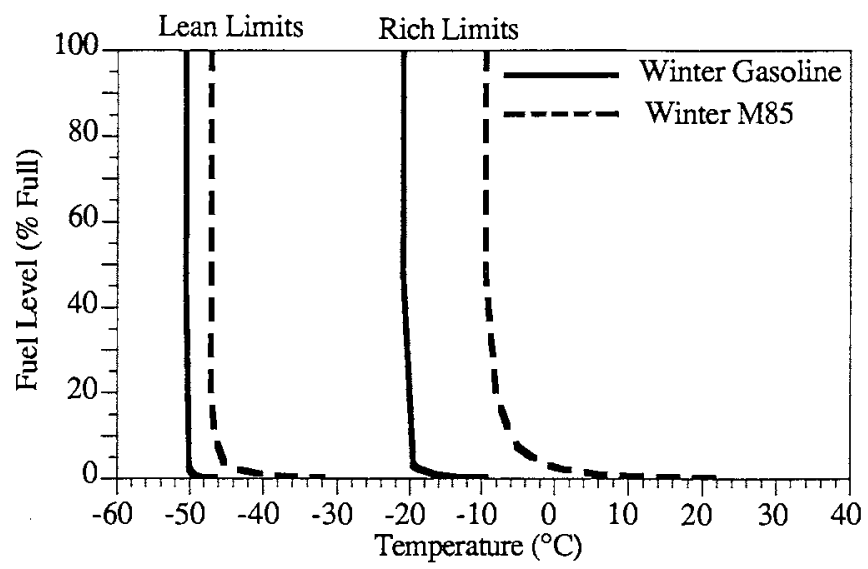

FIGURE 5: Flammable Range of Winter Gasoline and Winter M85

As a means of further illustrating the effect of fuel tank fill level on flammability, Figures 6 and 7 show a comparison of the predicted flammable ranges for the selected fuels at the $1 / 30$ th and $1 / 2$ fill levels. Comparing winter and summer gasoline in Figures 6 and 7 , it can be seen that, as the volatility decreases, the flammable range shifts to warmer temperatures and broadens slightly. The result of blending less volatile substances such as alcohols with gasoline is, of course, a fuel whose flammable range lies between those of the two components. These figures also show that the high alcohol blends exhibit greater sensitivity to fuel tank fill level than gasolines alone.

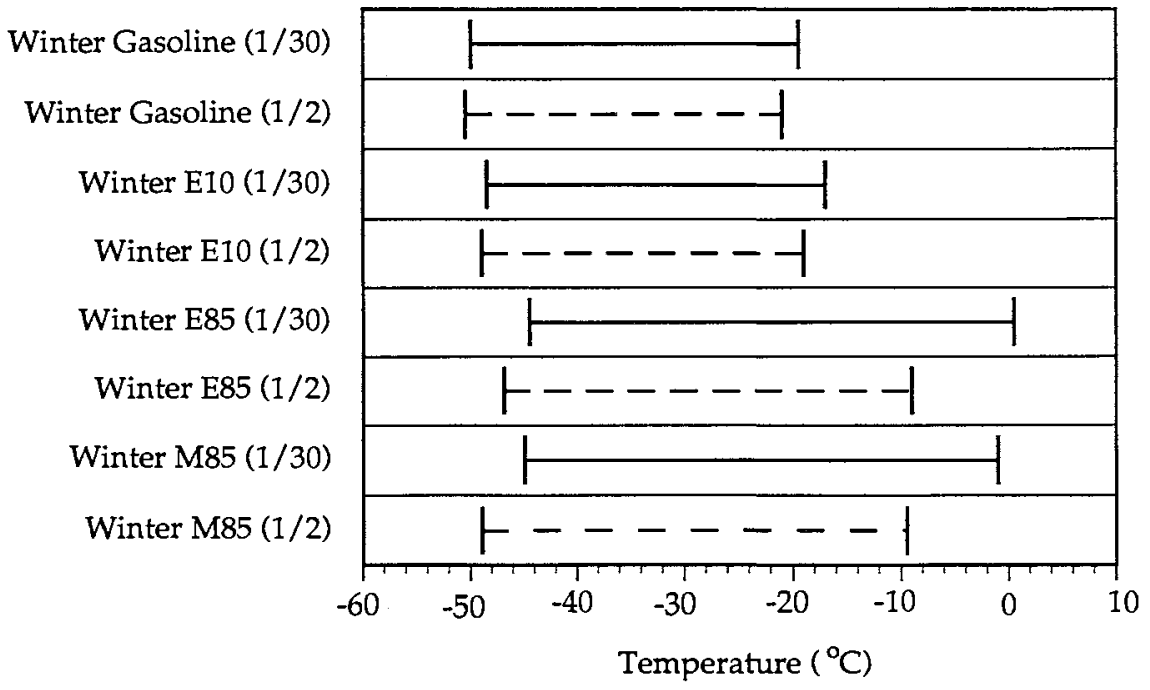

FIGURE 6: Predicted Effect of Fill Level on Flammable Range for Winter Fuels 


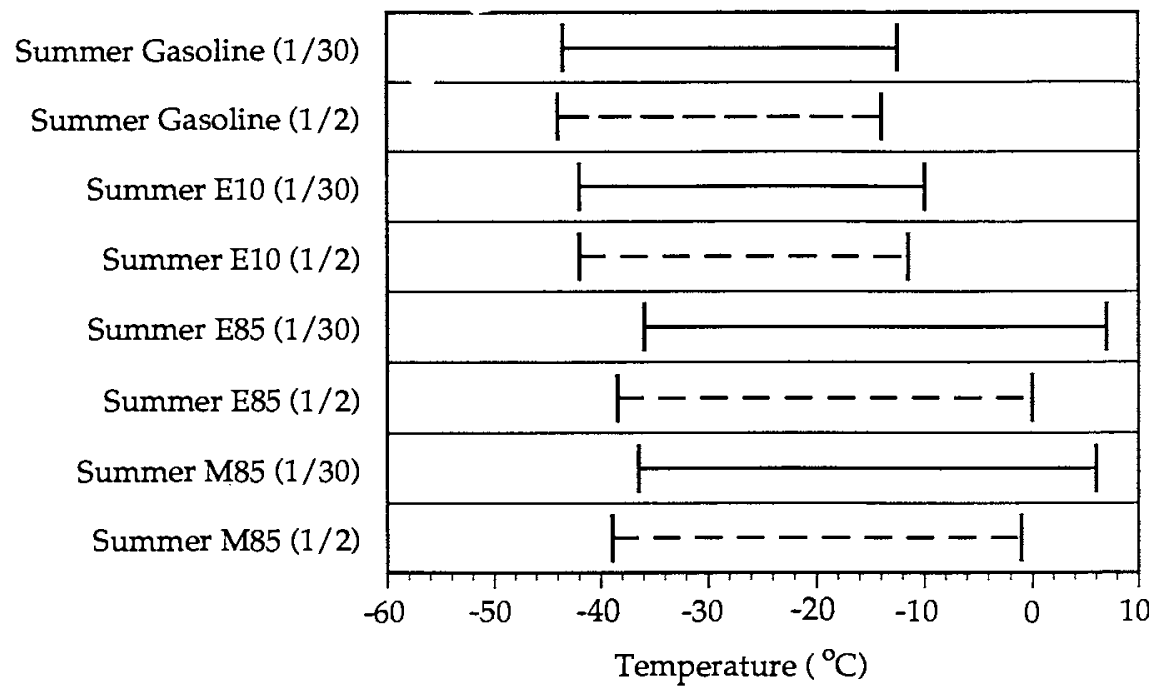

FIGURE 7: Predicted Effect of Fill Level on Flammable Range for Summer Fuels

\section{CONCLUSIONS}

1. The tests carried out in this program provide comparative data on the flammability of representative gasolines and alcohol-gasoline blends. The experimental results can be considered as indications of fundamental flammability limits rather than ignitability limits since a high energy ignition source was used in the tests.

2. The results show the tendency of the flammability limits both to broaden and to shift towards warmer temperatures with either decreasing fill level or increasing alcohol content.

3. The mathematical model provides reasonable predictions of the flammability limits for the fill level and fuels examined. Based on this agreement, it is concluded that the modelling techniques described may be used to provide estimations of flammability hazards under a wide range of conditions for fuels such as these studied.

4. Differences in fuel tank vapour flammability result in an increased hazard for high alcohol blends such as M85 or E85 compared to traditional high volatility gasolines. However, this study shows that gasoline is also more hazardous at winter temperatures than is commonly recognized and the trend towards reduced gasoline volatility increases the hazard still further for conventional fuels.

5. In light of the greater potential hazard with future fuels, including low volatility gasolines, additional safety precautions such as flame arrestors in fuel tank filler necks should be considered. The hazard presented by in-tank fuel pumps also warrants further study. 


\section{ACKNOWLEDGMENTS}

The assistance of A. Harrison and R. Mallory in the construction of the apparatus, D. Fisher and T. Chapman in the preparation of the manuscript, M. Gardiner in the flammability tests and D. McDill of the National Research Council of Canada in the gas chromatographic analysis is gratefully acknowledged.

\section{REFERENCES}

1. Bardon, M.F. and Rao, V.K., "Calculation of Gasoline Volatility", J. Inst. Energy, 57, pp.343-348, Sept. 1984.

2. Rao, V.K. and Bardon, M.F., "Estimating the Molecular Weight of Petroleum Fractions", Ind. Eng. Chem. Process Des. Dev., 27: 2, April, 1985.

3. Bardon, M.F., Rao, V.K., Vaivads, R. and Evans, M.J.B., "Measured and Predicted Effect of the Extent of Evaporation on Gasoline Vapour Pressure", L. Inst. Energy, 65 : 441, December 1986.

4. Bardon, M.F., Nicks, G.W., Rao, V.K. and Vaivads, R., "A Vapour Pressure Model for Methanol/Gasoline M85 Blends", SAE Paper \#870366 presented at the Intemational Congress and Exhibition, Detroit, Feb. 23-27, 1987.

5. Bardon, M.F. Rao, V.K., and Battista, V., "Modelling the Flammability Hazards of Methanol/Gasoline Blends", presented at the VIII International Symposium on Alcohol Fuels, Nov. 13-16, Tokyo, 1988.

6. Bardon, M.F., Rao, V.K., and Battista, V., "Volatility and Flammability of Methanol/Gasoline Blends, SAE Paper \#892062 presented at the International Fuels and Lubricants Meeting and Exposition Baltimore, September 25-28, 1989.

7. Bardon, M.F., Rao, V.K., "Estimating Instantaneous Properties of Vaporizing Light Petroleum Fractions," Combustion and Flame, 84: pp.427-431, 1991

8. "Vapour Pressure of Petroleum Products (Reid Method)", Test D323, American Society for Testing and Materials, Philadelphia, 1982.

9. "Distillation of gasoline, naptha, kerosine and similar petroleum products", Test D86, American Society for Testing and Materials, Philadelphia, 1978.

10. Vaivads, R.H., Bardon, M.F., Rao, V.K., "Flammability of Fuel Tank Headspace Vapours", Interim Report \#TE931001, Thermotech Engineering, Kingston, Oct. 1993.

11. Vaivads, R.H., Bardon, M.F., Rao, V.K., and Battista, V., "Volatility and Flammability of Variable Fuel Vehicle Tank Contents," SAE Paper \#932776, presented at the International Fuels and Lubricants Meeting \& Exposition, Philadelphia, PA, October 18-21, 1993.

12. Zabetakis, M.G., "Flammability Characteristics of Combustible Gases and Vapors", Bulletin 621, U.S. Bureau of Mines, Washington, 1965. 